\title{
Problematic Attachment to Social Media: the Psychological States vs Usage Styles
}

\author{
Majid Altuwairiqi ${ }^{1}$, Emily Arden-Close ${ }^{1}$, Nan Jiang ${ }^{1}$, Georgina Powell ${ }^{2}$, Raian Ali $^{1}$ \\ ${ }^{1}$ Bournemouth University, UK \\ \{maltuwairiqi, eardenclose, njiang, rali\}@bournemouth.ac.uk \\ ${ }^{2}$ Phone Life Balance Ltd - Creators of the SPACE App \\ georgie@space-app.com
}

\begin{abstract}
Many people worldwide rely on social media to satisfy their social needs for relatedness, learning and enhancing selfesteem. However, over-reliance on social media often results in problematic attachment, which risks personal, social and financial wellbeing. From a design perspective, we argue that social media can be improved with tools to manage such problematic attachment and help users reform their interaction style, social expectations and online identity to restore a healthy reliance. Designing such behaviour change tools can be challenging due to the characteristics of people with problematic behaviours, e.g. denial, relapse and cognitive dissonance. This paper explores the role of social media in such attachment and reveals associated psychological states. Our method provides an ecologically valid exploration through employing diary studies as a data collection method, aiming to introduce countermeasures for problematic attachment in future social media design.
\end{abstract}

Keywords—social media design, online behaviour, digital wellbeing

\section{INTRODUCTION}

Worldwide, individuals, particularly young people, are embracing the use of social media in their daily lives [1]. Social media enables people to engage with others, forming and maintaining relationships without the need to take part in real-life social activities [2]. Many use social media to connect with friends, organise events and express opinions, significantly affecting their everyday life and well-being.

The range of social media platforms has increased over time, facilitating communication and entertainment [3]. The number of active Facebook users was 500 million in 2010 but had increased to 2 billion by 2018 [4]. The rapid expansion in the use of social media has prompted academics to examine its impact. Recent studies advocate that social media can have both positive and negative impacts on users $[3,5]$.

Problematic attachment can be defined as over-reliance on social media to satisfy social and personal requirements, which can eventually harm personal and social wellbeing. People rely on social media to enhance their self-esteem [6] and maximise social capital [7]. This reliance can be problematic and cause impaired decision making, poor impulse control and anxiety, leading to excessive social media usage [8].

Social media addiction has been defined as compulsive use of social media, resulting in addictive behavioural symptoms [9]. Griffiths [10] noted addictive behavioural symptoms include: "convenience, tolerance, conflict, withdrawal, relapse, and mood modification". Although digital media addiction is not classified as a mental disorder in the Diagnostic and Statistical Manual of Mental Disorders (DSM) [11], given its possible impact on wellbeing, more research is needed.

Recent research concluded people with low self-esteem tend to overuse social media to enhance their self-image and self-esteem, e.g., [6, 12]. However, peer interaction and failure to obtain recognition may worsen their mood. Similarly, social media addiction is linked to anxiety, depression and stress. Moreover, it can contribute to poor academic performance and dissatisfaction with life [9]. Also, people who engage obsessively with social media are more likely to experience undesirable life experiences such as reduced creativity, increased anxiety and withdrawal from reality [13].

Despite social media being potentially problematic, it can also contribute to the solution by using software tools to help individuals self-regulate their social media addiction. Persuasive techniques can be incorporated into social media platforms to encourage healthy usage [14]. Unlike other addictions, technology can monitor its usage and report back to users, making them more informed and conscious of their usage [14]. For instance, users can request to receive notifications if their usage patterns suggest they are at risk as well as advice on how to combat the problem [15].

Existing literature on digital media addiction has mainly focused on psychological perspectives, such as the role of social skills [16] or personality traits [17], in facilitating digital media addiction. Certain patterns of social media use negatively impact psychological well-being [18]. However, there is limited research on the role of social media design in triggering problematic usage and regulating it. Further, it is uncertain how this would work beyond making people more aware of usage. The research identified a range of risks in software- behavioural change tools making their engineering complex and requiring a multidisciplinary approach combining expertise from information systems and psychology. Further research to enhance understanding of the role such software can play in combatting problematic attachment to social media is needed.

In this paper, we provide insights into the real-world experience of people with a problematic attachment to social media. We adopt a multi-stage qualitative research method using diary studies as a primary data collection technique to enhance the ecological validity of the study. We report on findings regarding psychological states experienced by the participants. The paper is aimed at informing a healthier use of 
social media and driving further development of behavioural change software tools for responsible social media usage.

\section{RESEARCH METHOD}

To obtain insights into problematic experiences on social media, we conducted a multi-phase qualitative study consisting of an exploratory phase (Section A) and a confirmatory and refinement phase (Section B). Different qualitative methods were employed in each phase to ensure the accuracy of the data capture and analysis. The data analysis and theoretical framework are described in Section C. The conceptual diagram of our research methods is presented in Fig.1.

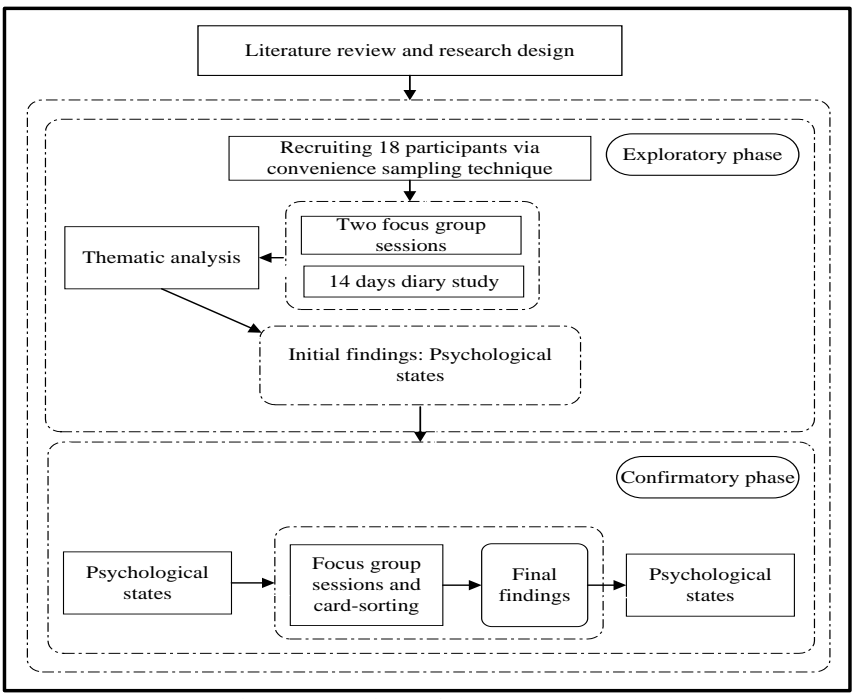

Fig. 1. Overview of the research method

\section{A. First Phase: Exploring Problematic Attachment}

This phase aimed to explore people's problematic attachment to social media. A qualitative method was adopted, involving focus groups and diary study methods. A focus group was used to gather initial insights, with the diary study capturing and refining users' problematic experience as lived.

Considering the representative population on social media and high social media usage in universities, participants were recruited using convenience sampling. Eighteen participants (nine male and nine female), were recruited from the authors' institution. Participants had to be 18 or over and self-identify as having a problematic attachment to social media.

The inclusion criteria were adhered to using a pre-selection questionnaire from the Generalised Problematic Internet Use Scale with necessary adaptations [19]. For example, "Internet" was replaced with "social media" to reflect the context.

We conducted two focus groups with nine participants each. The focus group study aimed to familiarise participants with the study objectives and obtain insights into their problematic relationship to social media. To prepare these participants for the diary study, at the end of each focus group session, training on using Evernote was provided. Evernote ${ }^{1}$ allows users to take notes, pictures, and recordings and regularly share them with the research team. The app also

${ }^{1}$ https://evernote.com/ allows the facilitator to send questionnaires to team workers. The diary study with the same 18 participants lasted two weeks and participants completed two tasks: 1) identifying their online styles and behaviour by emphasising their online presence. 2) detaching themselves from specific activities on social media, such as avoiding instant replies to their friends' messages, to discover accompanying side-effects. Participants provided their notes three times a day (morning, afternoon and night) using the Evernote application. Daily reminders were also sent. We then invited each participant to a face-to-face interview to discuss their entries.

\section{B. Second Phase: Refinement and Confirmation}

A closed card sorting technique within focus group sessions was carried out with 14 participants to refine the findings of phase one.

Six participants were selected from the exploratory phase sample to avoid analysis bias and to increase the credibility of the findings. This also served as a technique for member checking [20] to validate qualitative study findings. Eight other participants were recruited from a different cohort following the same recruitment procedure in the exploratory phase. A closed card sorting approach was used to refine the exploratory phase findings. The card sorting technique is useful for gaining participants' perspective regarding findings.

\section{Data Analysis}

The data collected from the interviews and the diary study was analysed using thematic analysis [21]. However, psychological states were the main findings of the analysis process. The published literature in problem gaming and substance abuse [10, 22], reinforced our findings in problematic behaviours. In light of this background, the nature of the social media platform was taken into account. The findings were also validated through the card sorting in the study's second phase.

\section{PRoBlematic ATtACHMENT to Social Media: FINDINGS}

Problematic attachment to social media and its design may reinforce psychological states triggered by interaction. We present psychological states and usage styles in Section A, psychological states and strengths in Section B, and problematic attachment and behavioural change tools in social media in IV.

\section{A. The Psychological States Vs Usage Styles}

People may experience psychological states depending on their interaction on social media. For example, problematic social media attachment may lead to psychological states such as craving, anxiety, loneliness, loss of interest, depression and boredom, contributing to the individuals' problematic attachment to social media. In Fig.2, we present frequent usage styles encountered by people with problematic attachment and related psychological states. The exploration of potential linkages between psychological states, e.g. anxiety and social media is complex and in its early stages [8, 23].

1) Craving: Craving can be defined as a conscious experience that occurs when an individual pays excessive attention to social media [24]. Perceived attractiveness of 
social media-related content increases with repeated online engagement. Craving manifests in problematic attachment to social media. Such craving to interact in social media allows individuals to adapt and strengthen their self-esteem, resulting in excessive and impulsive behaviours and ultimately generating negative effects [25]. When individuals re-form their online interaction style, cravings can be triggered by positive expectations, further fueling problematic attachment. The following are explanations for cravings arising concerning a problematic attachment:

- Increase reputation: Individuals with a problematic attachment to social media crave online interaction to increase their number of friends and likes, which in turn increases their reputation and social capital. This could involve excessively updating their user profile: "I feel craving because I want to increase my followers and bring life to my timelines".

- Daily routine: Individuals with problematic attachment to social media may develop a craving for social media because they habitually engage online as a daily routine, to eliminate craving. This encourages social media users to interact more than they need to improve their self-esteem and satisfy their needs; "I cannot imagine myself not using social media every day".

- Acquire intrinsic rewards: Individuals with problematic attachment to social media may feel negative about life. This triggers a desire for intrinsic rewards through online interaction, minimising their preoccupation with offline activities. Thus, individuals may engage online excessively to eliminate cravings for incentives [26]; "The first thing that comes to my mind when I want to feel pleasure, I go to social media”.

- Relapse to problematic style: Individuals might re-form a problematic attachment style on social media to regulate online interactions. Under some circumstances, their cravings could be provoked by positive expectations such as those maintained by popularity and relatedness, resulting in the compulsion for excessive interaction; "I minimised my online interaction pattern, but I felt that I might lose my social contacts. Then I feel a craving to increase them through online activities".

2) Anxiety: Anxiety that results from using social media can be defined as a sense of stress or worry. This is linked to the user's popularity, or how others perceive them on social media. Individuals with a problematic attachment to social media may feel anxious about their online interactions, which may negatively impact on their life satisfaction. Evidence supports the claim that excessive social media use interferes with work performance and undermines well-being [27]. Our exploratory study in Phase I revealed that individuals with problematic attachment might feel anxious during online interactions and that certain situations contribute to anxiety:

- Commitment to be highly responsive: Individuals with a problematic attachment to social media are anxious as a result of the commitment to stay constantly connected, causing challenges when they are unable to use their social media [28].

- Unconscious quick response: Individuals with a problematic attachment to social media may act quickly or unconsciously, resulting in a level of anxiety that negatively influences their well-being; "I cannot resist the urge to respond immediately to any activity on social media platforms. This makes me feel anxious".

- Excessive usage: Overuse of social media may cause anxiety regarding problematic attachment. Time spent online could conflict with user's duties and affect performance, in turn triggering anxiety; "I feel anxious when I am delaying important things that I have to do because of using social media for a longer time than I need".

- Displeasing content: Users feel anxious when social media content displeases them, often after receiving repetitive and ambiguous content, such as advertisements and anonymous friend requests, which could affect popularity if reposted. "I feel anxious when I receive an ambiguous email".

- Unmet expectations: Unmet expectations from an event on social media likely cause anxiety in individuals with a problematic attachment. For example, when users reformulate their presence and profile online this could lead to peer behaviour below the individual's expectations. They may not have received 'likes' on a post as expected, reducing their self-esteem and triggering anxiety.

3) Loneliness: This state arises when people feel a lack of authentic communication with others. Individuals with a problematic attachment to social media may feel lonely due to prolonged time spent on online interactions to maintain relationships and self-image [29]. From the exploratory study, two situations were identified regarding how participants experienced loneliness:

- Lack of accessibility: Inability to access social media

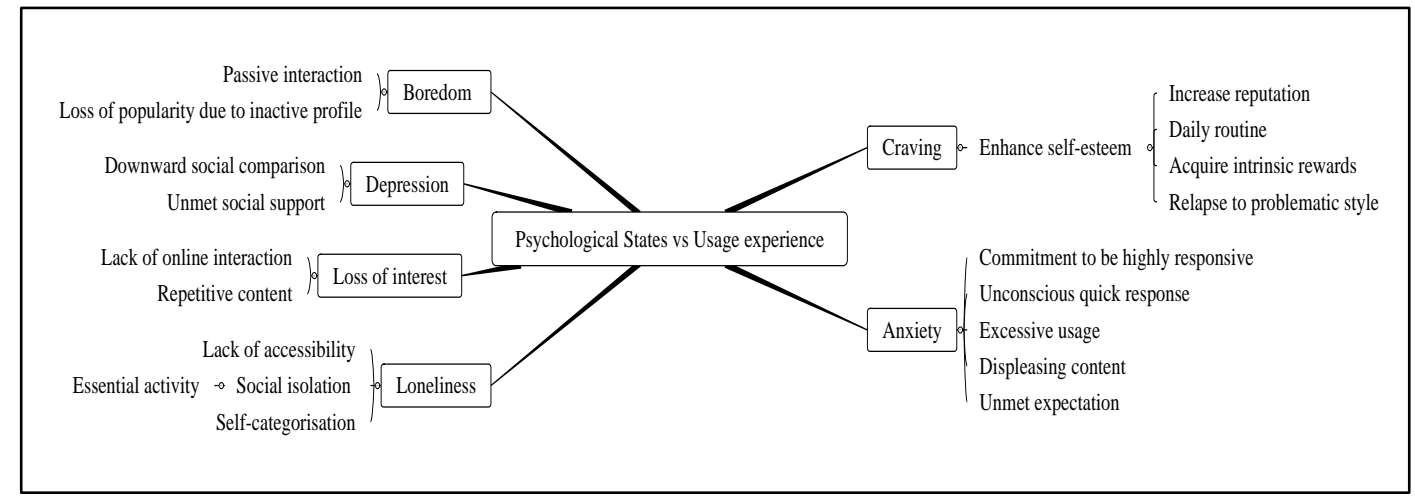

Fig. 2. Problematic Attachment to Social Media: the Psychological States Vs Usage Styles 
due to technical or personal factors, or failing to achieve an expected quantity and quality of interaction may trigger loneliness. This could increase in individuals with problematic attachment: "I felt lonely when I could not access my social media sites”.

- Social isolation: Individuals with a problematic attachment to social media are typically involved in a variety of online activities such as chatting, texting, posting and communicating with others, leading to excessive use of social media. Without self-control, such excessive interaction can increase the time spent online and provoke loneliness; "I feel isolated from the real world because I stay online most of my time”.

- Self-categorisation: Individuals classify themselves based on their class, age, gender and characteristics. For example, a user in Snapchat may classify themselves as a comedian, affecting their online behaviour. Selfcategorisation is related to group formation and membership, which depends on perceived similarities amongst group members in a particular context. This categorisation leads to self-evaluation, highlighting social isolation and provoking loneliness: "Social media is part of my life but I do not have many contacts because I only make contact with like-minded and educated people, I feel loneliness sometimes".

4) Loss of interest: Loss of interest refers to when individuals show no intention to maintain previously enjoyed social media activities. Individuals with problematic online attachment may feel less interested in social media, i.e. no longer caring about previously enjoyed activities, but being unable to reshape their relationship with it. The below situations illustrate how users experience this loss of interest:

- Lack of online interaction: Individuals with problematic attachment to social media experience a loss of interest without online interaction. Lack of online activities and friendships may lead to declining access to information and relatedness, which in turn decreases self-esteem and triggers loss of interest; "I am eager to Facebook, to know the news and communicate with others but I lose that desire if there is no continuous interaction".

- Repetitive content: Individuals with a problematic online attachment overly rely on social media to be aware of events and social communities. However, repetitive content in social media platforms may lead them to lose interest as they are used to receiving diverse content all the time; "New information and activities are exciting to me, but I may feel less interested to social media when the content is repetitive or outdated". Also, loss of interest can be bi-directional when users with problematic online attachment repost the same content through various social media platforms aiming to maximise outreach. This repetition may affect their popularity and relatedness due to others feeling less interested in their profiles: "I lost my popularity because people are less interested in following me posting the same content on my online profile”.
5) Depression: Depression is characterised by low selfworth or a sense of guilt and reduced ability to enjoy life. Social media allows an individual to form connections with others who share similar interests and consequently have greater social capital. Individuals with a problematic attachment to social media may feel depressed in the following situations:

- Downward social comparison: Social media users may engage in comparison with others, to meet selfevaluation needs. Social capital acquired, acceptance from others or online activities posted may give the impression that others are more prolific than them. This negative impression may provoke low self-evaluation and depression [30]; "I think life is not fair because I have a greater number of followers than my friend but frequently I see my friend getting more likes on his posts than me". People who spend excessive time on social media are likely to start social comparison with others, which could lead to depression [31].

- Unmet social support: Individuals with a problematic attachment to social media tend to have a high number of online friends [32]. Online communication methods such as messaging and posting, enable them to perceive support from their friends and establish intimacy with them, which can reduce depression [33]. When close friends are not available online to satisfy social support needs, individuals may feel depressed; "I think my close friends in social media are important for support and life happiness. However, I feel depressed when I do not find them online for an urgent situation".

6) Boredom: Boredom is experienced by individuals who have nothing to do either in social media or the real world. They are available online to occupy their free time and maintain connections with others. However, users with a problematic attachment to social media may experience boredom as explained below:

- Passive interaction: Online interaction may hurt selfesteem. With low self-esteem, the individual may engage in interaction such as scrolling passively, resulting in boredom; "I feel bored sometimes when using social media due to comparisons made. I then lose confidence because of those who are better than me in their posting. When this happens, I prefer to browse rather than posting".

- Loss of popularity due to inactive profile: Individuals may be occasionally inactive online, rarely posting even for their friends, negatively impacting on their popularity. Since their accounts appear inactive, other users no longer interact with them. This, in turn, provokes boredom; "Sometimes my interaction on social media is low which stops friends interacting with me and this makes me feel bored".

\section{B. Frequency and strengths of psychological states}

The study conducted a diary with 18 participants for 14 days with three daily diary entries. Out of a possible 756 diary entries, psychological states were provided in 712 entry 
documents. Table I summarises six emergent themes, their frequencies, and thematic exemplars. Exemplars were extracted from their original written documents as a means of adding "thickness" to the data [34].

TABLE I. FREQUENCY-PSYCHOLOGICAL STATES

\begin{tabular}{|c|c|c|c|c|}
\hline $\begin{array}{l}\text { Psychological } \\
\text { States }\end{array}$ & Frequency & Occurrences & $\%$ & Illustrative example \\
\hline Anxiety & $489 / 756$ & $\begin{array}{c}12 \\
\text { Participants }\end{array}$ & 64.68 & $\begin{array}{l}\text { When I upload photos } \\
\text { to Facebook, I feel so } \\
\text { anxious till I start to } \\
\text { receive a high number } \\
\text { of Likes. }\end{array}$ \\
\hline Boredom & $444 / 756$ & $\begin{array}{l}10 \\
\text { Participants }\end{array}$ & 58.73 & $\begin{array}{l}\text { I rely on social media } \\
\text { to change my mood } \\
\text { even at odd times of the } \\
\text { day. I feel so bored if } \\
\text { no one responds to my } \\
\text { posts and messages. }\end{array}$ \\
\hline Loneliness & $356 / 756$ & 9 Participants & 47.09 & $\begin{array}{l}\text { I feel isolated from } \\
\text { society because I stay } \\
\text { in my online gaming } \\
\text { groups most of time. }\end{array}$ \\
\hline $\begin{array}{l}\text { Loss of } \\
\text { Interest }\end{array}$ & $311 / 756$ & 8 Participants & 41.14 & $\begin{array}{l}\text { I overly check the } \\
\text { updates in social } \\
\text { media, but I quickly } \\
\text { lose interest and stop } \\
\text { reading, still cannot } \\
\text { stop checking }\end{array}$ \\
\hline Craving & $267 / 756$ & 6 Participants & 35.32 & $\begin{array}{l}\text { I can not wait to be } \\
\text { online and interact, it is } \\
\text { part of my daily routine } \\
\text { so not having it even } \\
\text { during work hours } \\
\text { would feel very strange }\end{array}$ \\
\hline Depression & $89 / 756$ & 3 Participants & 11.77 & $\begin{array}{l}\text { I do not compare } \\
\text { favourably to peers } \\
\text { profiles and posts on } \\
\text { social media. I stop } \\
\text { posting and continue } \\
\text { watching, and this } \\
\text { makes me feel at times } \\
\text { depressed }\end{array}$ \\
\hline $\begin{array}{l}\text { Entry doc. } \\
\text { with code(s) }\end{array}$ & 712 & $\begin{array}{c}18 \\
\text { participants }\end{array}$ & 94.12 & \\
\hline $\begin{array}{l}\text { Entry doc. } \\
\text { without } \\
\text { code(s) }\end{array}$ & 44 & & 5.88 & \\
\hline Analysed doc. & 756 & & 100.0 & \\
\hline
\end{tabular}

The large number of diary entries in this longitudinal study provides a good benchmark for how often such themes arise [35]. Frequency was computed via MAXQDA analysis software by identifying words such as anxiety, or phrases consisting of one of the variables. Almost all diary entries $(94.12 \%)$ included at least 1 of the items in the content of the states while engaging with social media. This can be inferred as an indicator of problematic online attachment. The results indicate a high frequency of anxiety (12 participants, representing $64.68 \%$ of feedback), but less depression (three participants $(11.77 \%)$.

\section{PRoblematic ATtaCHMENT AND BEHAVIOURAL CHANGE TOOLS IN SOCIAL MEDIA}

Users with problematic attachment are characterized by denial of their online behaviour; resistance, when they feel their freedom to use social media, is controlled by measures like reminders and timers, and relapse when they try to regulate that relationship both in terms of usage style and preoccupation [36]. Thus, social media design needs to consider differences between users in configurations of software-based intervention to meet the social and wellbeing needs of users [37]. Also, users showing problematic attachment may yearn to increase their reputation or feel anxious when unable to interact as wished. We identified negative psychological states that are facilitated by social media design, suggesting that the current design adopted by social media may impact negatively on users' wellbeing in the absence of any countermeasures to help self-regulation and mindfulness. People with poorer wellbeing may be more likely to use social media to alleviate loneliness.

Software is usually designed in line with user requirements. However, in this case, user requirements regarding social connectivity may contribute to problematic attachment to social media. Changes to software design to meet care needs are therefore needed. Software design with persuasive and gamification techniques can be used to reform people's problematic attachment to social media. However, ad hoc empowering of social media design by these tools may result in user side effects such as stress; leading to loss of engagement in the behaviour change process [38]. Co-creation methods integrate user perspectives with expert opinion and scientific evidence to develop interventions [39]. Participatory design has been used successfully to improve the dynamics and challenge of serious games for health promotion [40]. Participatory design methods may, therefore, help reduce this conflict by developing platforms acceptable to users, in terms of ease of use and need satisfaction, and developers, in terms of promoting wellbeing, in line with corporate responsibility.

It is also important that designs to target problematic attachment to social media do not lead to other issues. Individuals with problematic attachment tend to be anxious and may report that, e.g., checking notifications reduces their anxiety. Identifying designs of social media platforms that both improve wellbeing and reduce problematic usage is a challenge to be addressed. For example, decreasing notifications to individuals, while reducing checking, might increase anxiety in those who excessively checked social media. Also, limiting groups to certain times, while reducing the pressure to reply to messages at all hours, might lead to increased loneliness in users who have come to rely on the group for 24-7 support. A socio-technical approach could be needed, where human care combines with machine intelligence and software tools.

\section{CONCLUSION}

In this paper, we explored problematic attachment to social media presented by users' experiences. Our findings reveal psychological states associated with problematic attachments, indicating that problematic users rely on social media to satisfy their social requirements such as relatedness, learning and promoting self-esteem. They suggest that problematic attachment can be managed through tools which help users to reform their online interaction, expectations and online identity in a healthy manner. Design of these behavioural change tools is complicated by characteristics such as denial, relapse and cognitive dissonance. Most of the literature on the problem domain focused on user psychology. Further work will reveal psychological states associated with problematic attachment through real-time data such as sensors to promote crosssectional study. This will increase understanding and pave the way for clustering people with problematic attachment to 
social media by customising countermeasures, e.g. persuasive techniques to fit each group.

\section{REFERENCES}

[1] T. A. Pempek, Y. A. Yermolayeva, and S. L. Calvert, "College students' social networking experiences on Facebook," Journal of Applied Developmental Psychology, vol. 30, pp. 227-238, 2009.

[2] D. M. Boyd and N. B. Ellison, "Social network sites: Definition, history, and scholarship," Journal of computer - mediated Communication, vol. 13, pp. 210-230, 2007.

[3] G. S. O'Keeffe and K. Clarke-Pearson, "Clinical report - the impact of social media on children, adolescents, and families," Pediatrics, pp. peds. 2011-0054, 2011.

[4] Facebook. (2019). Facebook Newsroom. Available: https://newsroom.fb.com/company-info/

[5] M. Altuwairiqi, T. Kostoulas, G. Powell, and R. Ali, "Problematic attachment to social media: lived experience and emotions," in press.

[6] A. L. Gonzales and J. T. Hancock, "Mirror, mirror on my Facebook wall: Effects of exposure to Facebook on self-esteem," Cyberpsychology, Behavior, and Social Networking, vol. 14, pp. 79-83, 2011.

[7] C. Steinfield, N. B. Ellison, and C. Lampe, "Social capital, self-esteem, and use of online social network sites: A longitudinal analysis," Journal of Applied Developmental Psychology, vol. 29, pp. 434-445, 2008.

[8] H. C. Woods and H. Scott, "\# Sleepyteens: social media use in adolescence is associated with poor sleep quality, anxiety, depression and low self-esteem," J Adolesc, vol. 51, pp. 41-49, 2016.

[9] N. S. Hawi and M. Samaha, "The relations among social media addiction, self-esteem, and life satisfaction in university students," Social Science Computer Review, vol. 35, pp. 576-586, 2017.

[10] M. Griffiths, "A 'components' model of addiction within a biopsychosocial framework," Journal of Substance Use, vol. 10, pp. 191197, 2005.

[11] A. P. Association, Diagnostic and statistical manual of mental disorders (DSM-5®): American Psychiatric Pub, 2013.

[12] L. Denti, I. Barbopuolos, I. Nilsson, L. Holmberg, M. Thulin, M. Wendeblad, L. Andén, and E. Davidsson, "Sweden's largest Facebook study," 2012.

[13] C. S. Andreassen, "Online social network site addiction: A comprehensive review," Current Addiction Reports, vol. 2, pp. 175-184, 2015.

[14] A. Alrobai, K. Phalp, and R. Ali, "Digital Addiction: A Requirements Engineering Perspective," in International working conference on requirements engineering: Foundation for software quality (REFSQ), 2014, pp. 112-118.

[15] A. Alutaybi, J. McAlaney, A. Stefanidis, K. Phalp, and R. Ali, "Designing Social Networks to Combat Fear of Missing Out," in Proceedings of British HCI, 2018, p. 1.

[16] O. Turel and A. Serenko, "The benefits and dangers of enjoyment with social networking websites," European Journal of Information Systems, vol. 21, pp. 512-528, 2012.

[17] A. Winkler, B. Dörsing, W. Rief, Y. Shen, and J. A. Glombiewski, "Treatment of internet addiction: a meta-analysis," Clin Psychol Rev, vol. 33, pp. 317-329, 2013.

[18] E. Kross, P. Verduyn, E. Demiralp, J. Park, D. S. Lee, N. Lin, H. Shablack, J. Jonides, and O. Ybarra, "Facebook use predicts declines in subjective well-being in young adults," PLoS One, vol. 8, p. e69841, 2013.

[19] S. E. Caplan, "Problematic Internet use and psychosocial well-being: development of a theory-based cognitive-behavioral measurement instrument," Computers in Human Behavior, vol. 18, pp. 553-575, 2002.

[20] L. Birt, S. Scott, D. Cavers, C. Campbell, and F. Walter, "Member checking: a tool to enhance trustworthiness or merely a nod to validation?," Qualitative Health Research, vol. 26, pp. 1802-1811, 2016.
[21] V. Braun and V. Clarke, "Using thematic analysis in psychology," Qualitative Research in Psychology, vol. 3, pp. 77-101, 2006.

[22] R. Tao, X. Huang, J. Wang, H. Zhang, Y. Zhang, and M. Li, "Proposed diagnostic criteria for internet addiction," Addiction, vol. 105, pp. 556564, 2010.

[23] A. M. Shaw, K. R. Timpano, T. B. Tran, and J. Joormann, "Correlates of Facebook usage patterns: The relationship between passive Facebook use, social anxiety symptoms, and brooding," Computers in Human Behavior, vol. 48, pp. 575-580, 2015.

[24] J. M. Hormes, B. Kearns, and C. A. Timko, "Craving F acebook? Behavioral addiction to online social networking and its association with emotion regulation deficits," Addiction, vol. 109, pp. 2079-2088, 2014.

[25] A. Verdejo-García and A. Bechara, "A somatic marker theory of addiction," Neuropharmacology, vol. 56, pp. 48-62, 2009.

[26] D. N. Greenwood, "Fame, Facebook, and Twitter: How attitudes about fame predict frequency and nature of social media use," Psychology of Popular Media Culture, vol. 2, p. 222, 2013.

[27] S. A. Satici and R. Uysal, "Well-being and problematic Facebook use," Computers in Human Behavior, vol. 49, pp. 185-190, 2015.

[28] T. Ryan, J. Reece, A. Chester, and S. Xenos, "Who gets hooked on Facebook? An exploratory typology of problematic Facebook users," Cyberpsychology: Journal of Psychosocial Research on Cyberspace, vol. 10, 2016.

[29] M. Savci and F. Aysan, "Educational Process: International Journal," 2016.

[30] B. A. Feinstein, R. Hershenberg, V. Bhatia, J. A. Latack, N. Meuwly, and J. Davila, "Negative social comparison on Facebook and depressive symptoms: Rumination as a mechanism," Psychology of Popular Media Culture, vol. 2, p. 161, 2013.

[31] M.-L. N. Steers, R. E. Wickham, and L. K. Acitelli, "Seeing everyone else's highlight reels: How Facebook usage is linked to depressive symptoms," Journal of Social and Clinical Psychology, vol. 33, pp. 701731, 2014.

[32] C. Marino, L. Finos, A. Vieno, M. Lenzi, and M. M. Spada, "Objective Facebook behaviour: Differences between problematic and nonproblematic users," Computers in Human Behavior, vol. 73, pp. 541546, 2017.

[33] K. B. Wright, J. Rosenberg, N. Egbert, N. A. Ploeger, D. R. Bernard, and S. King, "Communication competence, social support, and depression among college students: a model of facebook and face-toface support network influence," Journal of health communication, vol. 18, pp. 41-57, 2013.

[34] J. G. Ponterotto and I. Grieger, "Effectively communicating qualitative research," The Counseling Psychologist, vol. 35, pp. 404-430, 2007.

[35] J. Neale, P. Miller, and R. West, "Reporting quantitative information in qualitative research: guidance for authors and reviewers," Addiction, vol. 109, pp. 175-176, 2014.

[36] J. Littrell, "How addiction happens, how change happens, and what social workers need to know to be effective facilitators of change," Journal of evidence-based social work, vol. 8, pp. 469-486, 2011.

[37] A. Shahri, M. Hosseini, M. Almaliki, K. Phalp, J. Taylor, and R. Ali, "Engineering software-based motivation: a persona-based approach," in Research Challenges in Information Science (RCIS), 2016 IEEE Tenth International Conference on, 2016, pp. 1-12.

[38] G. Drosatos, F. Nalbadis, E. Arden-Close, V. Baines, E. Bolat, L. Vuillier, T. Kostoulas, S. Wasowska, M. Bonello, and J. Palles, "Empowering Responsible Online Gambling by Real-time Persuasive Information Systems," presented at the Research Challenges in Information Science (RCIS), 2018.

[39] D. L. Sackett, W. M. Rosenberg, J. M. Gray, R. B. Haynes, and W. S. Richardson, "Evidence based medicine: what it is and what it isn't," ed: British Medical Journal Publishing Group, 1996.

[40] A. DeSmet, D. Thompson, T. Baranowski, A. Palmeira, M. Verloigne, and I. De Bourdeaudhuij, "Is participatory design associated with the effectiveness of serious digital games for healthy lifestyle promotion? A meta-analysis," Journal of medical Internet research, vol. 18, 2016. 